\author{
SuSANNA SCHELLENBERG \\ Rutgers
}

Perceptual Consciousness as a Mental Activity

\begin{abstract}
I argue that perceptual consciousness is constituted by a mental activity. The mental activity in question is the activity of employing perceptual capacities, such as discriminatory, selective capacities. This is a radical view, but I hope to make it plausible. In arguing for this mental activist view, I reject orthodox views on which perceptual consciousness is analyzed in terms of (sensory awareness relations to) peculiar entities, such as, phenomenal properties, external mind-independent properties, propositions, sense-data, qualia, or intentional objects.
\end{abstract}

When we attempt to reduce complex operations to simpler and simpler ones, we find in the end that discrimination or differential response is the fundamental operation. Discrimination is prerequisite even to the operation of denoting or 'pointing to'.

S. Stevens, 1939

What constitutes perceptual consciousness? The orthodox response is that perceptual consciousness is constituted by the entities of which we are sensorily aware when we are in a conscious perceptual state. There are two versions of this response. One version is to argue that perceptual consciousness is constituted by the external, mind-independent particulars, such as the cats, carrots, or cups, to which we are perceptually related in perception. Austere relationalists adopt this approach. ${ }^{1}$ A second version of the orthodox response is to argue that an experiencing subject stands in a sensory awareness relation to a peculiar entity and this peculiar entity or the sensory awareness relation to it constitutes perceptual consciousness. This peculiar entity has been understood in a multitude of ways. It has been understood to be a strange particular, such as a sense data, a quale, or a Meinongian object. It has been understood to be an abstract entity, such as a property, a property-cluster, an (uninstantiated) universal, a phenomenal property, a proposition, or an intentional object. ${ }^{2}$ As Dretske formulates the idea: "hallucinations are experiences in which one is aware of properties. ... Can we really be aware of (uninstantiated) universals? Yes, we can, and, yes, we sometimes are" (1999: 162-3). Let us call such views peculiar entity views. By 'peculiar entity' I mean any object that is not an external, mind-independent particular.

While peculiar entity views analyze perceptual consciousness as constituted by peculiar entities, austere relationalists analyze perceptual consciousness as constituted by the mind-independent particulars to which we are perceptually related in perception. What the views have in common is that they analyze perceptual consciousness as constituted by some entity, be it a mind-independent, external particular or a peculiar entity. So the orthodoxy that perceptual consciousness is 
constituted by the entities of which we are sensorily aware is a commitment of otherwise radically different views. Indeed, the idea is endorsed by views that disagree on almost everything else. Austere relationalists, qualia theorists, sense-data theorists, intentionalists, and most representationalists all endorse this orthodoxy.

There are deep problems with this orthodoxy. ${ }^{3}$ Therefore, I propose that we make a fresh start in our thinking about perceptual consciousness. I will argue that perceptual consciousness is constituted by a mental activity. More specifically, I will argue that perceptual consciousness is constituted by employing perceptual capacities, namely, discriminatory, selective capacities. This is a radical thesis, but I hope to make it plausible. The thesis that perceptual consciousness is constituted by a mental activity marks a profound break from the orthodoxy that perceptual consciousness is to be analyzed as constituted by the entities of which we are sensorily aware. I will show how this new way of understanding perceptual consciousness is more in tune with the empirical sciences than orthodox views of perceptual consciousness. While the view I will develop generalizes to non-perceptual forms of consciousness, I will, so as to keep the discussion tractable, focus on the case of perceptual consciousness.

In Section 1, I will develop the view that perceptual consciousness is constituted by a mental activity. I call this view mental activism. In Section 2, I will show that mental activism entails representationalism. Finally, in Section 3, I will show that mental activism does not require that a subject must have a history of employing perceptual capacities successfully in perception to employ a capacity in hallucination or illusion.

Throughout, I will operate with the ideal case of a so-called perfect hallucination, that is, a hallucination that has the same phenomenal character as a possible perception. Similarly, I focus on illusions that have the same phenomenal character as a possible perception. It is not relevant for my purposes whether a hallucination or an illusion could in fact have the same phenomenal character as a perception. I will assume for the sake of argument that such hallucinations and illusions exist and will explain how to understand their phenomenal character given this assumption. I focus on the case of such perfect hallucinations and illusions since they are the hardest cases to explain. The analysis of the phenomenal character of perfect hallucinations and illusions generalizes to an analysis of the phenomenal character of hallucinations and illusions that the experiencing subject would not mistake for a perception. So while I focus on the case of perfect hallucinations and illusions, the view of perceptual consciousness I develop holds for all forms of perception, illusion, and hallucination.

\section{Mental Activism}

Peculiar entity views are motivated by the fact that a hallucinating subject is not perceptually related to what it seems to her she is related to. Since the hallucinating subject is seemingly sensorily aware of something, she must stand in a sensory awareness relation to something that accounts for the phenomenal character of her hallucinatory state. Since she is not standing in a sensory awareness relation 
to the material, mind-independent particular that seems to her to be present, she must be standing in a sensory awareness relation to something else. With the aim of giving a common account of both perception and hallucination, most peculiar entity views hold that a perceiving subject is related to the very same (or the very same kind of) peculiar entity that she would be related to, were she hallucinating. Thus, most peculiar entity views are common factor views. Moreover, with the aim of analyzing perceptual consciousness in terms of a sensory awareness relation to something other than the material, mind-independent particulars present in perception, most common factor views analyze the common factor in terms of (a sensory awareness relation to) a peculiar entity. So, most common factor views are peculiar entity views.

I will develop a common factor view that does not amount to a peculiar entity view and I will argue that this common factor grounds perceptual consciousness. I avoid analyzing the common factor in terms of (a sensory awareness relation to) a peculiar entity by showing that hallucinations exhibit a deficiency that can only be explained with reference to accurate perceptions. So I propose that we do away with the old debates and approach the problem of consciousness in a radically different way. I will argue that perceptual consciousness is constituted by engaging in a mental activity, namely, the mental activity of employing perceptual capacities in a sensory mode, that is, modes such as seeing, hearing, touching, smelling, or tasting among others. ${ }^{4}$ We can call this view mental activism. Without further ado, the argument for mental activism goes as follows:

\section{The Argument for Mental Activism}

I. If a subject $S$ is perceptually related to particular $\alpha$, then $S$ is employing perceptual capacities $C$ by means of which she discriminates and singles out $\alpha$.

II. If $S$ is employing perceptual capacities $C$ by means of which she discriminates and singles out $\alpha$, then $S$ s phenomenal character is constituted by employing perceptual capacities $C$ by means of which she discriminates and singles out $\alpha$.

From I-II. If a subject $S$ is perceptually related to particular $\alpha$, then $S$ 's phenomenal character is constituted by employing perceptual capacities $C$ by means of which she discriminates and singles out $\alpha$.

III. If $S$ suffers an illusion or a hallucination as of $\alpha$, then $S$ 's phenomenal character is constituted by employing perceptual capacities $C$ by means of which she purports to discriminate and single out $\alpha$.

IV. If $S$ is perceptually related to $\alpha$ or suffers an illusion or a hallucination as of $\alpha$, then $S$ 's phenomenal character is constituted by employing perceptual capacities $C$, by means of which she (purports to) discriminates and singles out $\alpha$.

V. Employing perceptual capacities is a kind of mental activity. 
VI. If $S$ is perceptually related to $\alpha$ or suffers an illusion or a hallucination as of $\alpha$, then $S$ 's phenomenal character is constituted by a mental activity.

From I-VI. Phenomenal character is constituted by a mental activity.

In support of Premise 1, we can say that discriminating and singling out a particular from its surround is a minimal condition on perceiving the particular. After all, it is unclear what it would be to perceive a particular without at the very least discriminating and singling it out from its surround. Say that I perceive a red apple hanging from a tree. In perceiving the red apple, I will discriminate at least some of its properties from its surround. I may discriminate its red color from the green of the leaves around it. I may discriminate its round shape from the ovate shapes of the leaves around it. Or I may discriminate the smooth and shiny surface of the apple from the rougher, matte texture of the leaves. Such discriminatory activity allows for scene segmentation, border and edge detection, and region extraction. If there were no discriminatory activity, it is unclear how I could be perceptually aware of the apple. If this is right, then perception is constitutively a matter of employing perceptual capacities, that is, discriminatory, selective capacities.

Until the beginning of the $20^{\text {th }}$ century, it was standard to analyze mental states in terms of the capacities by means of which they were brought about (see among many others Aristotle's De Anima (1984) and Kant's Critique of Pure Reason (1781)). With the linguistic turn, this changed and it became standard to analyze mental states in terms of their content. While the linguistic turn brought about much progress with regard to clarity, giving up on analyzing mental states in terms of capacities came at a cost. Analyzing mental states in terms of capacities allows for a counterfactual analysis of the mind. But more importantly, we need not choose between analyzing mental states in terms of capacities and analyzing them in terms of their content. As I will argue in Section 2, insofar as perceptual capacities are repeatable and yield mental states that are either accurate or inaccurate with regard to the environment, employing perceptual capacities constitutes the representational content of perceptual states. So we can hold on to all the benefits of analyzing mental states in terms of capacities while reaping the benefits of analyzing them in terms of representational content. ${ }^{5}$

What are perceptual capacities? A perceptual capacity is a mental capacity that functions to differentiate, single out, and in some cases classify particulars of a specific type, such as instances of red (Julesz 1981, Krummenacher and Grubert 2010, and To and Gilchrist 2011). Such perceptual capacities are determined by general, functional relations between the organism and its environment - for instance, global patterns of the organism's response to its environment. If we possess the perceptual capacity that functions to differentiate and single out instances of red, we are in a position to differentiate instances of red from other colors in our environment and to single out instances of red. More generally, to possess a discriminatory, selective capacity is to be in a position to differentiate and single out particulars of the type that the capacity functions to single out, were one related to such a particular. It follows from the above that when we are perceptually related to a particular, we 
employ perceptual capacities by means of which we discriminate and single out the particular (Premise I).

The relevant particulars are external and mind-independent objects, events, property-instances, and instances of relations. The notion of property-instances in play is best illustrated with an example: when one sees two qualitatively identical white cups, the cups instantiate the same property, but the property-instances are distinct. When one suffers a hallucination as of a white cup, it seems to one that there is a white cup present, but since one is not perceptually related to the object that seems to be present, one is not perceptually related to any instance of whiteness.

Consider Percy who perceives a white cup on a desk. He employs his capacity to discriminate white from other colors and to single out white in his environment. $\mathrm{He}$ may also employ his capacity to differentiate and single out cup-shapes from other shapes in his environment. He may even employ his capacity to differentiate and single out cups from, say, computers and lamps, or whatever other objects may be in his environment. By employing such capacities, he is discriminating and singling out actual particulars in his environment. Engaging in this discriminatory activity allows him to detect the edge of the cup and segment the scene in front of him.

Percy can see the very same scene while employing perceptual capacities that are more or less fine-grained. For example, he may initially not attend to the fact that the rim of the cup is chipped, and so he may not employ his perceptual capacity to discriminate the grayish color of the part that is chipped from the white color of the unchipped parts. But then he might employ his more fine-grained perceptual capacity to discriminate between the various shades of white and gray on the cup. By employing perceptual capacities that are more fine-grained, the phenomenal character of his perceptual state will be more fine-grained in turn, and he will be sensorily aware of more details in his environment. So even if everything in the environment remains exactly the same, the phenomenal character of Percy's perceptual state may differ insofar as he employs more or less fine-grained perceptual capacities to single out the particulars in his environment.

As these examples illustrate, discrimination and perceptual consciousness are in lockstep. Indeed, we can say that any change in perceptual consciousness is either due to a change in the perceptual capacities employed or due to a change in the sensory mode in which those perceptual capacities are employed. If this is right, then any change in perceptual consciousness is due to a change in the mental activity by means of which we relate to our environment in perception. More precisely we can say that if a subject $S$ 's environment sensorily seems to contain $F$ particulars (regardless of whether it in fact does), then $S$ is in a phenomenal state that is constituted by employing perceptual capacities that function to single out $F$ particulars, where a phenomenal state is a perceptual state that is characterized by a specific phenomenal character. So, phenomenal character is constituted by employing perceptual capacities by means of which we discriminate and single out the particulars to which we are perceptually related (Premise II).

How can we extend this analysis of perceptual consciousness to hallucinations and illusions? To answer this question, let's consider the fact that if we possess a concept, then we can employ it even if we fail to refer. After all, if we say "That's 
a horse," pointing to where in fact there is no horse, we are arguably using the very same concept HORSE that we would use if we were successfully pointing at a horse. The failure occurs at the level of reference. There is no failure at the level of employing the concept.

The very same thing can be said of perceptual capacities. If we possess a perceptual capacity, then we can employ it even if we are not accurately perceiving. Although perceptual capacities are determined by functional connections between perceivers and their environment, arguably they can be employed even if one is misperceiving, hallucinating, or suffering a hallucination. After all, the capacities are determined by general, functional relations between the organism and its environment-for instance, global patterns of the organism's response to its environment - and not by individual token responses. One could be prompted to employ such capacities due to nonstandard circumstances: Unusual brain stimulations or misleading distal inputs. If this is right, then we can employ a discriminatory, selective capacity even if a relevant particular is not present - where a relevant particular is a token of the type that the capacity functions to single out. The capacities employed account for the fact that in hallucinations we can purport to single out particulars: From a first-person perspective it can seem as if we were perceptually related to particulars in our environment.

If this is right, then we can say that when we hallucinate or suffer an illusion, we employ the very same capacities that we would employ in a perception with the same phenomenal character. Since in cases of illusion and hallucination, we are not perceptually related to at least one of the particulars that we purport to single out, we fail to single out at least one particular. We merely purport to single out that particular. As a consequence, at least one of the perceptual capacities is employed baselessly, in the sense that the target of discrimination and selectionan external, mind-independent particular-is absent. Analogously, if we employ a concept but fail to refer, the concept employed remains empty. If one employs a perceptual capacity in an environment in which no particular that the capacity functions to single out is present, then one fails to single out what the perceptual capacity purports to single out. As in the case of concepts, the failure occurs at the level of singling out a particular. There is no failure at the level of employing the capacity (Premise III).

Consider Hallie who suffers a hallucination as of a white cup on a desk. Like Percy, she employs the capacity to discriminate and single out white from other colors and she employs the capacity to differentiate and single out cup-shapes from, say, computer-shapes and lamp-shapes. Since she is hallucinating rather than perceiving and so is not perceptually related to a particular white cup, she employs these capacities baselessly. Yet even though she fails to single out any particular white cup, she is in a phenomenal state that is as of a white cup, in virtue of employing perceptual capacities that purport to single out a white cup. As in the case of perception, employing these perceptual capacities constitutes her phenomenal character. So what perception, hallucination, and illusion have in common is that perceptual capacities are employed that constitute the phenomenal character of the relevant experiential states. 
The difference between Hallie and Percy is simply that while Hallie fails to single out what she purports to single out, Percy succeeds. There is no reason to think that whether we succeed in singling out what our perceptual capacities function to single out has any repercussions for the phenomenal character of our experiential state. After all, there is no difference in phenomenal character if I employ perceptual capacity $C$ to single out $\alpha$ or if I employ perceptual capacity $C$ to single out $\beta$, where $\alpha$ and $\beta$ are qualitatively identical yet numerically distinct particulars. If that is right, then we should not expect there to be a difference in phenomenal character if I employ $C$ to single out $\alpha$ or if I employ $C$ while failing to single out a particular. We can distinguish the employment of a capacity - what perceptions, hallucinations, and illusions have in common-from discriminating and singling out a particular - the matter on which perceptions, hallucinations, and illusions differ. It is the employment of the capacity that constitutes perceptual consciousness. Whether a particular is singled out does not affect perceptual consciousness. Only if this is the case, can the view explain how a perception, a hallucination, and an illusion could have the same phenomenal character and thus avoid a disjunctivist view of phenomenal character. Since perceptual consciousness is constituted by employing perceptual capacities, it is not revealed in perceptual consciousness whether the capacities are employed baselessly and so whether we are perceiving, hallucinating, or suffering an illusion (Premise IV). Furthermore, insofar as employing perceptual capacities is a kind of mental activity, this implies that phenomenal character is constituted by a mental activity (Premises V and VI).

If it is right that two experiential states in which all the same perceptual capacities are employed in the same sensory mode have, ceteris paribus, the same phenomenal character, then there is a metaphysically substantial common factor between perceptions, hallucinations, and illusions. That common factor is constituted by the perceptual capacities that the subject employs in a sensory mode. As I will show shortly, the fact that there is such a common factor neither implies that we are aware of a common factor, nor does it imply that the good case is to be analyzed as a conjunction of a common factor and some additional element, such as a causal perceptual relation.

Before I show how mental activism amounts to a modestly externalist view about perceptual consciousness, I will address two potential misconceptions. First, we possess and make use of many discriminatory, selective capacities that are not phenomenally relevant - even when we perceive. I have not argued that whenever we use such a capacity, we are in a phenomenal state. I have argued only that phenomenal states should be understood as constituted by employing perceptual capacities in a sensory mode. We can accept this thesis while acknowledging that there are many capacities - including discriminatory, selective capacities - the employment of which has no repercussions for our conscious mental lives.

Second, it is crucial that employing discriminatory, selective capacities is not just a matter of differentiating particulars, but also of singling out particulars. Due to this, the phenomenal character of perceiving an instance of red is distinct from the phenomenal character of perceiving an instance of blue. Both cases may include differentiating red and blue, but in the former case an instance of red is singled out, 
while in the latter case an instance of blue is singled out. So the capacities employed are distinct and the phenomenal states differ.

\subsection{Mental Activism and Modest Externalism about Perceptual Consciousness}

So far I have shown how mental activism posits a common element between perception, hallucination, and illusion at the level of employing perceptual capacities. Now I will argue that at the level of the function of perceptual capacities, there is a primacy of the employment of capacities in perception over their employment in hallucination or illusion. In virtue of this primacy, mental activism is an externalist view of perceptual consciousness. So I will argue that while at the level of employing perceptual capacities, perception, hallucination, and illusion are on a par, at the level of the function of perceptual capacities there is a primacy of perception over hallucination and illusion.

I have argued that perceptual consciousness is constituted by employing perceptual capacities in a sensory mode. These capacities are, however, in turn analyzed in terms of the external, mind-independent particulars that they function to single out. There is a primacy of the employment of perceptual capacities in perception over their employment in hallucination or illusion insofar as perceptual capacities are determined by relations between perceivers and the particulars they function to single out. After all, the function of the capacity is to differentiate and single out, say, instances of red in perception and in the case of a successful perception the capacity does just that. Thus, perceptual consciousness is inherently related to the particulars that perceptual capacities single out in the good case. So given the properties of perceptual capacities, perceptual consciousness is externally determined.

This approach allows us to recognize the austere relationalist insight that perceptual consciousness can and should be explained in terms of perceptual relations to the very external, mind-independent particulars of which a perceiver is aware. Austere relationalists argue that perceptual consciousness should be understood in terms of a sensory awareness or acquaintance relation to particulars in the perceiver's environment. This insight demystifies perceptual consciousness. However, by arguing for the radical thesis that all there is to perceptual consciousness is to be perceptually related to one's environment, austere relationalists leave mysterious how one could be in a phenomenal state if one is not perceiving, but rather suffering an illusion or a hallucination. ${ }^{6}$

By recognizing that a minimal condition on perception is that the perceiving subject discriminates particulars in her environment, we open the door to acknowledging that perceiving particulars is a matter of employing perceptual capacities that function to discriminate and single out particulars. By introducing such perceptual capacities, we can reject the radical austere relationalist thesis. By rejecting the radical austere relationalist thesis, the mental activism provides not just an account of the phenomenal character of perception, but an account also of the phenomenal character of hallucinations.

So, against austere relationalists, I have argued that perceptions and hallucinations share a common element that constitutes their phenomenal character. However, with austere relationalists, I have argued that hallucinations exhibit a deficiency 
that can only be explained with reference to accurate perceptions. Hallucinations are derivative of perceptions insofar as the perceptual capacities employed in hallucinations can only be specified with reference to their possible role in perception. I have argued that to possess a perceptual capacity is to be in a position to discriminate and single out particulars that the capacity functions to single out in the good case, that is, the case in which one is perceptually related to such a particular. Since perceptual capacities are analyzed in terms of perceptual relations to external, mind-independent particulars, mental activism amounts to a naturalized view of perceptual consciousness. $^{7}$

\subsection{Intensional Perceptual Consciousness and Extensional Sensory Awareness}

While standard views analyze perceptual consciousness in terms of awareness relations to peculiar entities, mental activism acknowledges that a hallucinating subject does not stand in a sensory awareness relation to anything despite being in a phenomenal state that purports to be of mind-independent particulars. To defend the conjunction of these two theses it will be helpful to uncover a key structural difference between perceptual consciousness and sensory awareness. For a subject to be sensorily aware of a particular implies that the subject stands in a sensory awareness relation to that very particular. So a subject cannot be sensorily aware of the particular $\alpha$ without standing in a sensory awareness relation to $\alpha$. Indeed, being sensorily aware of $\alpha$ entails the existence of $\alpha$. In this sense, sensory awareness is factive. Peculiar entity views analyze perceptual consciousness in terms of that of which we are sensorily aware. Such views take it that a hallucinating subject must be sensorily aware of some entity, where that entity constitutes the phenomenal character of the hallucination. Since she is not sensorily aware of any external, mind-independent particular that she seems to be seeing, such views conclude that she must be sensorily aware of a peculiar entity. Similarly, austere relationalists analyze perceptual consciousness in terms of sensory awareness relations to particulars. The difference between the peculiar entity view and austere relationalism is simply that the former has it that we are sensorily aware of peculiar entities, while the latter has it that we are sensorily aware of external, mind-independent particulars.

If we recognize that perceptual consciousness need not be analyzed in terms of that of which we are sensorily aware, we can circumvent any commitment to both austere relationalism and the peculiar entity view. Consider a subject who is in a phenomenal state, that is, an experiential state that is characterized by perceptual consciousness. We can all agree that for a subject to be in a phenomenal perceptual state is for her to be in an experiential state that purports to be of something. So far there is no reason to say that she is sensorily aware of something. After all, for a phenomenal state to purport to be of $\alpha$ does not imply that the subject is aware of $\alpha$ (or of anything else). Being in a phenomenal state does not entail the existence of that of which the mental state purports to be of. Moreover, being in a phenomenal state does not entail the existence of some other entity to which the subject stands in a sensory awareness relation. It follows that a subject can be in a phenomenal state without standing in a sensory awareness relation to any entity. So there is a structural difference between awareness of, on the one hand, 
and perceptual consciousness or being in a phenomenal state, on the other. While awareness of is extensional, perceptual consciousness or being in a phenomenal state is intensional.

Austere relationalist and peculiar entity views are structurally similar in that they both analyze perceptual consciousness extensionally. By doing so both views conflate perceptual consciousness with sensory awareness. Some views go as far as to equate that which constitutes perceptual consciousness with that of which the experiencing subject is sensorily aware. ${ }^{8}$ The idea that perceptual consciousness is extensional goes back to at least Moore, who assumed that all sensory awareness involves an object of awareness (Moore 1925: 54).

It is important to note that denying that a hallucinating subject stands in a sensory awareness relation to an object (or some other particular) is not to deny the linguistic fact that the expression "I hallucinate" takes a grammatical object. Even so, there is no need to take this grammatical object to correspond to an ontological existent of which the hallucinating subject is sensorily aware. The grammatical object merely marks what the hallucinating subjects takes to be present and what she would be sensorily aware of, were she perceiving an external, mind-independent object.

This structural difference between sensory awareness and perceptual consciousness is analogous to the distinction between relational and phenomenological particularity. A mental state is characterized by relational particularity if and only if the experiencing subject is perceptually related to the particular perceived and the perceived particular constitutes the mental state. A mental state exhibits phenomenological particularity only if it seems to the subject as if there is a particular present. Every experience that is subjectively indistinguishable from a perception exhibits phenomenological particularity. After all, it is unclear what it would be to have an experience that seems to be as of an external, mind-independent particular without it seeming to the subject that there is a particular present. Since the hallucinating subject is not perceptually related to the mind-independent particular that it seems to her is present, hallucinations are not characterized by relational particularity. More generally, we can say that if a subject has an experience that is intentionally directed at a particular, it will seem to her as if she is experiencing a particular-regardless of whether there is in fact such a particular present. If this is right, then any view on which a perception, illusion, or hallucination is intentionally directed at the experiencer's environment is committed to saying that such experiences exhibit phenomenological particularity.

Now, one may wonder how such an account can secure the identity of hallucinated objects across hallucinations. It cannot, but this is a desirable consequence of the view. A hallucinating subject may form false judgments on the basis of her hallucinations and believe that the unicorn it seemed to her she saw yesterday is the very same unicorn as the one that it seems to her she is seeing today. But the identity postulated here is within the scope of how things seem to the subject and thus based on mere phenomenological particularity. There is nothing in the world that corresponds to how things seem to the hallucinating subject, and thus there is nothing in the world that corresponds to this phenomenological particularity. In 
other words, the phenomenological particularity of her experience is not coupled with any relational particularity. Since the subject is not sensorily aware of any unicorn, no identity of the hallucinated objects can be secured.

\subsection{Blurriness and Afterimages}

The discussion so far has focused exclusively on perceptual consciousness (as) of particulars that are either located in the environment of the perceiving subject, or which merely seem to be so located, as in the case of an illusion or a hallucination. There are, however, aspects of perceptual consciousness, such as blurriness and afterimages, that do not pertain to (seemingly) material, mind-independent particulars. ${ }^{9}$ For example, upon removing a pair of prescription glasses, one experiences blurriness. It will not, however, necessarily seem to one as if the environment is blurry (though, of course, that can happen). Similarly, if one presses against one's closed eyes, one can experience color patches in one's visual field - even after reopening one's eyes. As in the case of experiencing blurriness, it will not necessarily seem to one that the color patches are colors instantiated in one's material, mind-independent environment (though, again, that may happen). How can mental activism account for such aspects of perceptual consciousness that do not seem to the experiencing subject to pertain to the material, mind-independent environment?

A blurry experience of a white cup can be analyzed in terms of employing the perceptual capacity that functions to single out instances of blurriness (along with employing the perceptual capacity that functions to single out instances of white and the perceptual capacity that functions to single out the relevant shapes in one's environment, and so forth). The perceptual capacity that functions to single out blurriness is grounded in perceptions of instances of blurriness: When I look out of the window on a rainy day, the tree in front of my window is presented blurrily to me because of the raindrops on the window. Now, seeing something as blurry is of course distinct from seeing something blurrily, but the very same perceptual capacity of blurriness can be understood to be employed in both experiences. The difference between seeing something as blurry and seeing something blurrily can be accounted for in virtue of what blurriness is attributed to. If one experiences an object as blurry, blurriness is attributed to that object. If one experiences blurrily, blurriness is attributed to one's experience. In this way, mental activism undermines the need to appeal to qualia, sensations, phenomenal properties, or any other peculiar entities to account for aspects of perceptual consciousness that do not pertain to particulars that are either located in the environment or that seem to be located in the environment of the experiencing subject.

\section{Mental Activism as a Version of Representationalism}

So far, I have argued that perceptual consciousness is constituted by a mental activity. Now I will show how this view is in fact a version of representationalism. Any view on which perceptual consciousness is said to be grounded in representational content needs to explain what it is about representational content such that it can ground perceptual consciousness. Employing perceptual capacities just is to be in 
a perceptual state with content. After all, perceptual capacities are repeatable and constitute a phenomenal state that either accurately or inaccurately accounts for how the environment really is. Being repeatable and having accuracy conditions are jointly key signatures of semantic content. I will give support to each claim in turn.

The very same perceptual capacity can be employed to single out particular $\alpha$ or to single out particular $\beta$. As argued in the last section, if one singles out $\alpha$ rather than $\beta$, one is in a distinct perceptual state, namely, a perceptual state that is constituted by $\alpha$ rather than $\beta$. This is the case even if $\alpha$ and $\beta$ are qualitatively identical. So the same perceptual capacity can be employed in distinct environments and yield distinct perceptual states. If this is right, then there is a general, repeatable element that is constitutive of perceptual states, namely, the perceptual capacities employed. Moreover, the same perceptual capacity can be employed to single out $\alpha$ at time $t_{1}$ and at time $t_{2}$ and thus yield the same perceptual state at $t_{1}$ and $t_{2} .{ }^{10}$ In this sense, employing repeatable perceptual capacities generates a perceptual state that is itself repeatable. Being a repeatable capacity is of course not a sufficient condition for yielding a semantic mental state. After all, many things in the world are constituted by repeatable capacities without yielding semantic mental states. Being repeatable is however arguably a necessary condition on yielding a semantic mental state. Now, when one discriminates and singles out a particular from its surround, one may do so more or less accurately or inaccurately, and the perceptual state reached will be more or less accurate or inaccurate thereby. ${ }^{11}$ After all, a perceiver can single out an object and correctly single out only very few of its properties; or she can single out the same object and correctly single out many of its properties. The first perceptual state will be less accurate with regard to the environment than the second. ${ }^{12}$ So employing perceptual capacities yields perceptual states that exhibit key signatures of semantic content: It yields something that is repeatable and that can be accurate or inaccurate. If this is right, then employing perceptual capacities constitutes a perceptual state with content. ${ }^{13}$ Insofar as employing perceptual capacities just is to be in a perceptual state with content, mental activism is a version of representationalism.

So mental activism is both a view of perceptual consciousness and a specific interpretation of the thesis that perceptual consciousness is grounded in representational content. On most representationalist views, it is either left mysterious how the representational content could in fact ground the perceptual consciousness of the representational state, or perceptual consciousness is ultimately explained in terms of awareness relations to peculiar entities. Recall, for example how Dretske (1999) - the ultimate representationalist - argues that in hallucination we are aware of universals. As I argued earlier, this view is deeply problematic insofar as it is not clear what it would be to be sensorily aware of properties, given that properties are not spatio-temporally extended, not spatio-temporally located, and not causally efficacious. In contrast to such views, I am arguing that perceptual consciousness is grounded in representational content in that representational content is yielded by employing perceptual capacities which constitute perceptual consciousness. ${ }^{14}$

I have argued that both perceptual consciousness and perceptual content are constituted by employing perceptual capacities. One might object that since 
perceptual consciousness and perceptual content are different in kind, they cannot both be constituted by the same activity. In response, no doubt, perceptual consciousness and perceptual content are different in kind. The latter, but not the former, is propositionally structured. We can honor this even if we accept that both are constituted by employing perceptual capacities. After all, perceptual content is only partially constituted by employing perceptual capacities. It is constituted also by the particulars singled out. Similarly, perceptual consciousness is constituted not only by the perceptual capacities employed but also by the sensory mode in which those perceptual capacities are employed. But even if it were the case that both perceptual content and perceptual consciousness were constituted exclusively by employing perceptual capacities that would not be a problem. After all, $A$ and $B$ can be different in kind, even if $A$ and $B$ are each constituted by $\rho$. For example, bread and spaghetti are different in kind and both are constituted by wheat. In short, there is no problem in endorsing the thesis that perceptual consciousness and perceptual content are each constituted by employing perceptual capacities.

\section{Grounded and Ungrounded Perceptual Capacities}

Now, how should we understand the relation between being perceptually related to external, mind-independent particulars, such as white cups, and employing perceptual capacities that merely purport — but ultimately fail — to single out any such particulars? To address this question, it will be necessary to distinguish three possible ways of analyzing perceptual capacities.

On a first way of analyzing perceptual capacities, a perceptual capacity need not in any way be grounded in perception. So on this version, hallucinations or illusions as of particulars are possible even if no one has perceived the relevant particulars (perhaps because the relevant particulars do not exist). We can call this version ungrounded perceptual capacities. On this version, one can employ a perceptual capacity in hallucination or illusion that has never been employed to successfully discriminate and single out an external, mind-independent particular of the kind that the capacity functions to single out.

On a second way of analyzing perceptual capacities, any perceptual capacity is grounded in perceptions of the very perceiver employing the perceptual capacity derivatively in hallucination or illusion. So it is necessary to have employed any given perceptual capacity in perception to be in a position to employ that same perceptual capacity derivatively in hallucination or illusion. We can call this version radically grounded perceptual capacities. This version posits that the content of hallucination or illusion is derivative of the content of perception insofar as it ensues from reemploying and possibly recombining the perceptual capacities one has employed in past perceptions. A view that is committed to radically grounded perceptual capacities faces the problem that one can only have a hallucination or an illusion as of a particular if one has perceived such a particular in the past.

On a third way of analyzing perceptual capacities, any perceptual capacity is grounded in perception, but it is not necessary that perceptual capacity is grounded 
in perceptions of the very perceiver employing the perceptual capacity derivatively in hallucination or illusion. The perceptual capacity can be grounded in perceptions of some perceiver somewhere. So a perceiver can have hallucinations or illusions as of particulars even if she has no past perceptions of the relevant particulars. While the perceptual capacity is grounded in perception, it need not be grounded in past perceptions of the very subject who is suffering a hallucination or an illusion as of the particulars that the capacity functions to single out. We can call this version modestly grounded perceptual capacities. This version allows that a subject could have a hallucination or an illusion as of a particular unlike anything she has seen before. However, some bridge must exist between my hallucination or illusion as of a particular that I have never seen and someone else's perception of a relevant particular. Only if some such bridge exists can the perceptual capacity I employ in hallucination or illusion be plausibly understood to be grounded in accurate perceptions. The perceptual capacities employed in such hallucinations or illusions could be acquired via testimony from a perceiver who has used the capacity in perception.

We can reject radically grounded perceptual capacities. After all, the perceptual capacities employed in hallucinations need not have been acquired through perceptions. They might be innate, they might have been acquired through testimony, or they might have been arrived at through imagination. Mental activism requires only that that we must be in a position to use a perceptual capacity successfully when perceptually related to a particular that the capacity functions to single out.

While it is possible to possess such a capacity without having been perceptually related to any particulars of the type that the capacity singles out in the good case, it is plausible that any such perceptual capacity is grounded in perception insofar as the existence of the capacity depends on perceptions of the particulars that the capacity singles out. ${ }^{15}$ If this is right, then it follows that there cannot exist any such perceptual capacity that is not grounded in perception. It does not, however, follow from this that an individual subject must have had perceptions of the particulars that the capacity singles out to possess the relevant capacity. It follows only that there can exist a perceptual capacity that functions to single out a kind of particular only if a particular of that kind has been perceived by someone, somewhere.

We can remain neutral here whether perceptual capacities are ungrounded or modestly grounded. Mental activism is compatible with perceptual capacities being ungrounded or being modestly grounded. On both ungrounded and modestly grounded perceptual capacities, a subject need not have had perceptions of particulars to have hallucinations or illusions as of such particulars. So both ways of analyzing perceptual capacities posit that a brain in a vat could have hallucinations as of white cups. If perceptual capacities are ungrounded, then an isolated brain in a vat could have such hallucinations.

Can Jackson's Mary hallucinate a red object? ${ }^{16}$ Mary is a color scientist who knows everything about colors but who lives in a black and white world and so has never seen any colors. So she could not have acquired the perceptual capacity to discriminate and single out red through perceptions of instances of red. 
According to mental activism it is not necessary to have perceived instances of red to hallucinate a red object. So Mary could hallucinate a red object while in her black and white world. ${ }^{17}$

\section{Coda}

I developed the view that perceptual consciousness is constituted by a mental activity. According to mental activism, perceptual consciousness is constituted by employing perceptual capacities, that is, low-level mental capacities that function to discriminate and single out particulars in our environment. Mental activism is a version of representationalism. After all, employing perceptual capacities constitutes perceptual content. As a consequence, mental activism is a common factor view: perceptions, hallucinations, and illusions with the same phenomenal character have a metaphysically, substantial common factor that is constituted by the perceptual capacities employed. Thus mental activism avoids any commitment to disjunctivism.

As I showed, there is no need to think that employing perceptual capacities entails the existence of the particulars that the perceptual capacities purport to single out. So mental activism allows that we can be in a mental state that is characterized by perceptual consciousness without being sensorily aware of any external, mindindependent particulars. A subject who is suffering a hallucination or an illusion as of what seems to her to be a mind-independent particular $\alpha$ employs a perceptual capacity that functions to single out mind-independent particulars under which $\alpha$ falls. The perceptual capacity she employs is the very same perceptual capacity that in a perception with the same phenomenal character is employed as a consequence of the perceiving subject being related to the external, mind-independent particular $\alpha$ or some such particular. Employing such a perceptual capacity accounts for the fact that it seems to the subject that $\alpha$ is present and accounts for her being intentionally directed at what seems to be an external, mind-independent particular without in fact being sensorily aware of $\alpha$ or any other such particular. Thus, mental activism avoids analyzing perceptual consciousness as constituted by (sensory awareness relations to) peculiar entities - be they phenomenal properties, external mind-independent properties, propositions, sense-data, qualia, or intentional objects.

So mental activism reconciles the following three theses. First, the view does not require positing that hallucinating or perceiving subjects stand in a sensory awareness relation to peculiar entities. In this respect, the view is ontologically more minimalist than any view that must appeal to such entities and thus upholds Quinean commitments to ontological minimalism. Second, the view gives a positive account of the phenomenal character of hallucinations and, in this respect, is an improvement over austere relationalism or austere relationalism. Finally, the view analyzes perceptual consciousness, in terms of employing perceptual capacities, where perceptual capacities are in turn individuated by the mind-independent particulars they function to single out. Thereby, mental activism amounts to a naturalized view of perceptual consciousness. ${ }^{18}$ 


\section{Notes}

${ }^{1}$ For a defense of austere relationalism or naïve realism, see Campbell (2002), Martin (2002), Brewer (2006), Genone (2014), and French (2014) among others. For recent critical discussions, see Schellenberg (2010), (2011a) and Echeverri (2016).

${ }^{2}$ For views according to which hallucinating subjects stand in awareness or acquaintance relations to property-clusters, see Johnston (2004); for (uninstantiated) properties, see Dretske (1995), Byrne (2001), Tye (2002), Hill (2006), (2009), Pautz (2007), Siegel (2011), Mendelovici (2013), and Statzicker (2016); for phenomenal properties, see Chalmers (2006), Block (2007); for propositions, see Russell (1913); for intentional objects, see Harman (1990), Lycan (1996); for sense-data, see Robinson (1994); for qualia, see Levine (1983), Chalmers (1996), Block (2003), McLaughlin (2007); for Meinongian objects, see Parsons (1980). It is important to note that one could argue that hallucinating subjects represent intentional objects without arguing that perceivers stand in awareness or acquaintance relations to such objects. For a defense of such a view, see Crane (1998). There are ways of understanding qualia on which they are simply identified with phenomenal character, such that any phenomenological state necessarily instantiates qualia. This understanding of qualia implies that experiences trivially instantiate qualia. But if that is all that is meant with qualia, then introducing qualia just amounts to a reformulation of the fact that experiences are phenomenal states. For a discussion of this set of issues, see Stoljar (2004). Block analyzes qualia in terms of neural states. So for Block the final level of analysis is not qualia but rather neural states. In that sense his view is more powerful than views on which the final level of analysis is qualia. It should be noted that it has been argued that if inverted spectrum scenarios are empirically possible, then introducing qualia is necessary, where qualia are understood as more substantive than simply what can be identified with phenomenal character (Shoemaker 1982). However, as Egan (2006) has argued convincingly, it can be ruled out on conceptual grounds that inverted spectrum scenarios are empirically possible. Finally, one can argue that the content of a hallucination is a Russellian proposition without arguing that hallucinating subjects stand in awareness or acquaintance relations to these propositions or their constituents. However, arguably, any view that aims to explain phenomenal character in virtue of properties or objects that constitute perceptual content is committed to holding that the experiencing subject stands in an awareness or acquaintance relation to these properties or objects. For a defense of this thesis, see Crane (2006): 128ff. It would lead too far afield to discuss here to what extent such views are peculiar entity views. I will reserve this for another occasion. For the purposes of this paper, any view that denies that subjects stand in awareness or acquaintance relations to peculiar entities is not my target. I will address such views only to the extent that they face the same problems as peculiar entity views. For a recent account of consciousness and an overview of the current debate, see Hill (2009).

${ }^{3}$ See Schellenberg (2011b) for a critical discussion of this orthodoxy.

${ }^{4}$ Here and throughout, 'constituted' is understood in the sense of at least partially constituted. This leaves open whether there might be other determinants. There are many sensory modes that are not perceptual sensory modes. For example, kinesthesia is a sensory mode, but arguably not a perceptual sensory mode. I am here focusing on those sensory modes that are relevant for perception, though my argument would have to be adapted only slightly to generalize to phenomenal states that are not perceptual states. For discussion of olfaction, see Batty (2010); for tactile experiences, see Fulkerson (2011); for taste, see Smith (2007); for auditory experiences, see Nudds (2001), O'Callaghan (2010), Phillips (2012), Wu and Cho (2013). See Macpherson (2011) for different ways of individuating the senses. See DeRoy et al. (2014) for a discussion of a multisensory conception of perception, and DeRoy (2014) and de Vignemont (2014) on multimodal unity and binding.

${ }^{5}$ Analyzing mental states in terms of capacities has recently seen a revival. Sosa's virtue epistemology, for example, recognizes capacities (or competences) as the foundational level of explanation (2007, 2015). This paper contributes to that revival.

${ }^{6}$ For a defense of this radical austere relationalist thesis, see Campbell (2002), Brewer (2006), and Fish (2009). Martin (2004) argues for a more moderate version of austere relationalism.

${ }^{7}$ Externalism about perceptual consciousness is arguably the best approach to developing a naturalized account of perceptual consciousness. However, see William (2004) for an argument that dualism, 
which often goes hand in hand with phenomenal internalism, is not in conflict with a naturalistic approach to the mind.

${ }^{8}$ See, for example, Harman (1990), Dretske (1995), Lycan (1996), Tye (2002), Brewer (2006), Fish (2009), and Hill (2009).

${ }^{9}$ Visual blur is often posed as a problem for the transparency thesis. For more discussion on blur, see Smith (2008), Allen (2013), French (2014), Schroer (2002), and Speaks (2009, 2014). For other recent challenges to the transparency thesis, see Kind (2003) and Howell (2016).

${ }^{10}$ One could argue that different time-slices bring about a difference in perceptual states. If one holds this, then the relevant perceptual state would be different, but it would be different only in this respect.

${ }^{11}$ One might object here that not all discriminatory capacities yield things that have accuracy conditions. For example, thermometers discriminate temperatures, but we do not say that the state thereby produced has accuracy conditions. In response, it is apt to say that the temperature indicated by the thermometer either matches the temperature in the environment or fails to match the temperature in the environment. In this sense, the state of the thermometer in which it indicates a particular temperature has accuracy conditions. Thanks to Neil Mehta for pressing me on this point.

${ }^{12}$ For a discussion of the relationship between singling out objects and singling out the properties this object instantiates, see Pylyshyn and Storm (1988), Pylyshyn (2007), and Fodor (2008).

${ }^{13}$ See Schellenberg (2011a), (2012), (2013), (2014), and (2016) for a defense of this view.

${ }^{14}$ Orlandi (2010) has argued that there is little empirical ground to suppose that sensory properties, such as color, are represented in perceptual experience. If true, this would not present any challenge to mental activism, whereas it would pose a prima facie challenge to views according to which in perception a subject represents properties.

${ }^{15}$ This is not implied by the argument of the chapter. The phenomenal evidence argument requires only a weaker claim, namely, that any perceptual capacity is grounded in how things would come out in the good cases. However, for empiricist reasons independent of the argument of this chapter, it is plausible to assume that such capacities are grounded in actual perceptions and not just possible perceptions. For a discussion of such reasons, see Goodman (1955).

${ }^{16}$ See Jackson (1982), (1986).

${ }^{17}$ For a discussion of experiences of novel colors, see Macpherson (2003).

${ }^{18} \mathrm{I}$ am indebted to audiences at Stanford University, University of California Santa Cruz, UNAM, Mexico City, Rice University, the Bochum-Rutgers Workshop in New York City, the CUNY Cognitive Science Group, Universität Tübingen, the Clark Lecture at Indiana University, Universitat de Barcelona, University of Pittsburgh, the Portuguese Society for Analytic Philosophy National Meeting on the Azores, the Metaphysics of Mind Conference at Fordham University, National Chung Cheng University, Taiwan. I am grateful also to John Morrison and his graduate students for discussions in his graduate seminar at Columbia as well as Nico Orlandi for discussions in her seminar at UCSC and detailed written comments. Thanks are due also to Austin Baker, Ned Block, Laura Callahan, Rosa Cao, Megan Feeney, Danny Forman, Manuel Garcia-Carpintero, Kevin Kimble, Kirk Ludwig, Alexander Morgan, Krista Lawlor, Thomas Sattig, Miguel Ángel Sebastián, Eli Shupe, Charles Siewert, Josefa Toribio, and Hong Yu Wong, for helpful discussions.

\section{References}

Allen, K. 2013. "Blur." Philosophical Studies 162: 257-73.

Almäng, J. 2013. "The Causal Self-Referential Theory of Perception Revisited." Dialectica 67: $29-53$.

Aristotle 1984. De Anima, trans. J. A. Smith. Reprinted in The Complete Works of Aristotle, ed. J. Barnes. Princeton: Princeton University Press.

Bach, K. 2007. "Searle Against the World: How Can Experiences Find their Objects." John Searle"s Philosophy of Language: Force, Meaning, and Mind, ed. S. L. Tsohatzidis. Cambridge: Cambridge University Press.

Batty, C. 2010. "A Representational Account of Olfactory Experience." Canadian Journal of Philosophy 40: $511-38$. 
Block, N. 1990. “Inverted Earth.” Philosophical Perspectives 4, ed. J. Tomberlin. Northridge: Ridgeview Publishing Company.

2003. "Mental Paint." Reflections and Replies: Essays on the Philosophy of Tyler Burge, ed. M. Hahn and B. Ramberg. Cambridge: MIT Press.

2006. "Max Black"s Objection to the Mind-Body Identity." Phenomenal Concepts and Phenomenal Knowledge, ed. T. Alter and S. Walter. Oxford: Oxford University Press.

2007. "Consciousness, Accessibility, and the Mesh between Psychology and Neuroscience." Behavioral and Brain Sciences 30: 481-548.

Brewer, B. 2006. "Perception and Content." The European Journal of Philosophy 14: 165-81.

Burge, T. 2010. Origins of Objectivity. Oxford: Oxford University Press.

Byrne, A. 2001. "Intentionalism Defended." The Philosophical Review 110: 199-240.

Campbell, J. 2002. Reference and Consciousness. Oxford: Oxford University Press.

2009."Consciousness and Reference." Oxford Handbook of Philosophy of Mind, ed. B. McLaughlin and A. Beckermann. Oxford: Oxford University Press.

Chalmers, D. 1996. The Conscious Mind. Oxford: Oxford University Press.

—. 2004. "The Representational Character of Experience." The Future of Philosophy, ed. B. Leiter, Oxford: Oxford University Press.

2006. "Perception and the Fall from Eden." Perceptual Experience, ed. T. Gendler and J. Hawthorne. Oxford: Clarendon Press.

Crane, T. 1998. "Intentionality as the Mark of the Mental." Contemporary Issues in the Philosophy of Mind, ed. A. O’Hear. Cambridge: Cambridge University Press.

2006. "Is there a Perceptual Relation?" Perceptual Experience, ed. T. Gendler and J. Hawthorne. Oxford: Oxford University Press.

Davies, M. 1992. "Perceptual Content and Local Supervenience." Proceedings of the Aristotelian Society 92: $21-45$.

DeRoy, O. 2014. "Multimodal Unity and Multimodal Binding." Sensory Integration and the Unity of Consciousness, ed. C. Hill and D. Bennett. Cambridge: MIT Press.

DeRoy, O., Chen Y. C., Spence C. 2014. "Multisensory Constraints on Awareness." Philosophical Transactions of the Royal Society Philosophical Transactions of the Royal Society B: Biological Sciences 369: 20130207-20130207.

de Vignemont, F. 2014. "A multimodal conception of bodily awareness." Mind 123: 989-1020.

Dretske, F. 1995. Naturalizing the Mind. Cambridge: MIT Press.

1999. "The Mind's Awareness of Itself." Philosophical Studies 95: 103-24.

Echeverri, S. 2016. "Illusions of Optimal Motion, Relationalism, and Perceptual Content." Pacific Philosophical Quarterly 97: 1-23.

Egan, A. 2006. "Appearance Properties?" Noûs 40: 495-521.

ffytche, D. H. and Howard, R. J. 1999. "The Perceptual Consequences of Visual Loss. 'Postive' pathologies of Vision." Brain 122: 1247-60.

2008. "The Hodology of Hallucinations." Cortex 44: 1067-83.

Fish, W. 2009. Perception, Hallucination, and Illusion. Oxford: Oxford University Press.

Fodor, J. 1998. Concepts: Where Cognitive Science Went Wrong. New York: Oxford University Press.

2008. LOT2: The Language of Thought Revisited. Oxford: Oxford University Press.

French, C. 2014. "Naïve Realist Perspectives on Seeing Blurrily." Ratio 27: 393-413.

Fulkerson, M. 2011. "The Unity of Haptic Touch." Philosophical Psychology 24: 493-516.

Genone, J. 2014. "Appearance and Illusion." Mind 123: 339-76.

Harman, G. 1990. "The Intrinsic Quality of Experience.” Philosophical Perspectives 4, ed. J. Tomberlin. Northridge: Ridgeview Publishing Company.

Hill, C. 2009. Consciousness. Cambridge: Cambridge University Press.

Howell, R.H. J. 2016. "Perception from the First-Person Perspective." European Journal of Philosophy 24: $187-213$.

Jackendoff, R. 1987. Computation and Cognition. Cambridge: MIT Press.

Jackson, F. 1977. Perception: A Representative Theory. Cambridge: Cambridge University Press.

1982. "Epiphenomenal Qualia." Philosophical Quarterly 32: 127-36. 
1986. "What Mary Didn”t Know."Journal of Philosophy 83: 291-95.

Johnston, M. 2004. "The Obscure Object of Hallucination." Philosophical Studies 120: 113-83.

Julesz, B. 1981. "A Theory of Preattentive Texture Discrimination Based on First-Order Statistics of Textons." Biological Cybernetics 41: 131-8.

Kant, I. 1781. Kritik der reinen Vernunft. Critique of Pure Reason, trans. N. K. Smith (1965). New York: St. Martin"s Press.

Kriegel, U. 2011. "The Veil of Abstracta." Philosophical Issues 21: 245-67.

Krummenacher, J., Grubert A.et al, 2010. "Inter-Trial and Redundant-Signals Effects in Visual Search and Discrimination Tasks: Separable Pre-Attentive and Post-Selective Effects." Vision Research 50: $1382-95$.

Levine, J. 1983. "Materialism and Qualia: The Explanatory Gap.” Pacific Philosophical Quarterly 64: 354-61.

Lycan, W. G. 1996. Consciousness and Experience. Cambridge, MA: MIT Press.

MacPherson, F. 2003. "Novel Colors and the Content of Experience." Pacific Philosophical Quarterly 84: 43-66.

—. 2011. "Individuating the Senses." The Senses: Classical and Contemporary Readings, ed. F. Macpherson. Oxford: Oxford University Press.

Malik, J. and Perona, P. 1990. "Preattentive Texture Discrimination with Early Vision Mechanisms Effects." Journal of the Optical Society of America 7: 923-32.

Martin, M.G.F. 2002. "Particular Thoughts and Singular Thoughts." Logic, Thought and Language, ed.

A. O'Hear. Cambridge: Cambridge University Press.

McGinn, C. 1982. The Character of Mind. Oxford: Oxford University Press.

McLaughlin, B. 2007. "Type Materialism for Phenomenal Consciousness." Blackwell Companion to Consciousness, ed. M. Velmans and S. Schneider. Oxford: Blackwell Publishing.

Mendelovici, A. 2013. "Reliable Misrepresentation and Tracking Theories of Mental Representation". Philosophical Studies 165: 421-43.

Millar, A. 2007. "What the Disjunctivist is Right about." Philosophy and Phenomenological Research 74: $176-99$.

Mizrahi, V. 2009. "Is Color Composition Phenomenal?" Color Perception: Physiology, Processes and Analysis, ed. D. Skusevich and P. Matikas. New York: Nova Science Publishers.

Moore, G.E. 1925. "A Defence of Common Sense" Contemporary British Philosophy, ed. J. H. Muirhead. (Reprinted in G. E. Moore, Philosophical Papers, 1959).

1953. Some Main Problems of Philosophy. London: George, Allen and Unwin.

Nudds, M. 2001. "Experiencing the Production of Sounds." European Journal of Philosophy 9: 210-229.

O'Callaghan, C. 2010. Sounds: A Philosophical Theory. Oxford: Oxford University Press.

Orlandi, N. 2010. "Are Sensory Properties Represented in Perceptual Experience?" Philosophical Psychology 23: 721-740.

Parsons, T. 1980. Nonexistent Objects. New Haven: Yale University Press.

Pautz, A. 2007. "Intentionalism and Perceptual Presence." Philosophical Perspectives 21, ed. J. Hawthorne. Northridge: Ridgeview Publishing Company.

Peacocke, C. 1992. A Study of Concepts. Cambridge: MIT Press.

Phillips, I. 2012. "Hallucinating Silence." Hallucination, ed. F. Macpherson and D. Platchias, Cambridge MA: MIT Press.

Pylyshyn, Z. W. 2007. Things and Places: How the Mind Connects with the World. Cambridge, MA: MIT Press.

Pylyshyn, Z. W. and R. W. Storm. 1988. "Tracking Multiple Independent Targets: Evidence for a Parallel Tracking Mechanism." Spatial Vision 3: 179-97.

Price, H. H. 1950. Perception. London: Methuen.

Prinz, J. 2002. Furnishing the Mind: Concepts and their Perceptual Basis. Cambridge, MA: MIT Press.

Robinson, H. 1994. Perception. London: Routledge.

Robinson, W. 2004. Understanding Phenomenal Consciousness. Cambridge: Cambridge UP.

Russell, B. 1913. Theory of Knowledge: London: Routledge 1992.

Sagi, D. and Julesz, B. 1985. "Detection versus Discrimination of Visual Orientation." Perception 14: $619-28$. 
Schellenberg, S. 2010. "The Particularity and Phenomenology of Perceptual Experience.” Philosophical Studies 149: 19-48.

2011a. "Perceptual Content Defended." Noûs 45: 714-50.

2011b. "Ontological Minimalism about Phenomenology." Philosophy and Phenomenological Research 83: 1-40.

2012. "Sameness of Fregean Sense." Synthese, special volume edited by R. Briggs, 189: 163-75.

2013. "Externalism and the Gappy Content of Hallucination". Hallucination, ed. F. E. Macpherson and D. Platchias, Cambridge: MIT Press, pp. 291-311.

2014. "The Relational and Representational Character of Perceptual Experience." Does Perception have Content?, ed. B. Brogaard. Oxford: Oxford University Press.

2016. "Perceptual Particularity." Philosophy and Phenomenological Research 93: 25-54.

Schroer, R. 2002. "Seeing It All Clearly: The Real Story on Blurry Vision." American Philosophical Quarterly 39: 297-301.

Shoemaker, S. 1982. "The Inverted Spectrum." The Journal of Philosophy 79: 357-81.

Siegel, S. 2011. The Contents of Visual Experience. Oxford: Oxford University Press.

Smith, A. D. 2002. The Problem of Perception. Cambridge, MA: Harvard University Press. 2008. "Translucent Experiences." Philosophical Studies 140: 197-212.

Smith, B. 2007. "The Objectivity of Taste and Tasting." Questions of Taste: The Philosophy of Wine, ed. B. Smith, Oxford: Oxford University Press.

Snowdon, P. 1981. "Perception, Vision and Causation." Proceedings of the Aristotelian Society 81: $175-92$.

Sosa, E. 2007. A Virtue Epistemology: Apt Belief and Reflective Knowledge. New York: Oxford University Press.

2015. "The Unity of Action, Perception, and Knowledge." Judgment and Agency, E. Sosa. Oxford: Oxford University Press.

Speaks, J. 2009. "Transparency, Intentionalism, and the Nature of Perceptual Content." Philosophy and Phenomenological Research 79: 539-73.

2014. Transparency and Availability: An Essay in the Philosophy of Perception. Oxford: Oxford University Press.

Stazicker, J. 2016. "The Visual Presence of Determinable Properties.” Phenomenal Presence, ed. F. E. Macpherson, F. Dorsch, and M. Nida-Rümelin. Oxford: Oxford University Press.

Stevens, S. S. 1939. "Psychology and the Science of Science." Psychological Bulletin 36: 221-263.

Stoljar, D. 2004. "The Argument from Diaphanousness." New Essays in the Philosophy of Language and Mind. Supplemental volume of The Canadian Journal of Philosophy, ed. M. Ezcurdia, R. Stainton, and C. Viger. Calgary: University of Calgary Press.

Strawson, P.F. 1979. "Perception and its Objects." Perception and Identity, ed. G. F. MacDonald. London: Macmillian.

Sundström, P. 2013. "Are Colors Visually Complex?" Johanssonian Investigations: Essays in Honour of Ingvar Johansson on His Seventieth Birthday, ed. C. Svennerlind, J. Almäng, and R. Ingthorsson. Frankfurt: Ontos Verlag.

To, M.P., Gilchrist I.D. et al. 2011. "Discrimination of Natural Scenes in Central and Peripheral Vision." Vision Research 51: 1686-98.

Travis, C. 2004. "Silence of the Senses." Mind 113: 57-94.

Tye, M. 2002. "Representationalism and the Transparency of Experience." Noûs 36: 137-51.

Watson, A. and Robson, J 1981. "Discrimination at Threshold: Labelled Detectors in Human Vision." Vision Research 21: 1115-22.

Wilson, K. 2013. "Reid's Direct Realism and Visible Figure." The Philosophical Quarterly 63: 783-803.

Wu, W. and Cho, R. 2013. "Mechanisms of Auditory Verbal Hallucination in Schizophrenia." Frontiers in Schizophrenia 4. 